\title{
PERCEPÇÕES DOS AGENTES COMUNITÁRIOS DE SAÚDE SOBRE AS AÇÕES DE PROMOÇÃO DA SAÚDE
}

\author{
COMMUNITY HEALTH WORKERS' PERCEPTIONS ON THE ACTIONS OF HEALTH PROMOTION
}

\section{Lislaine Aparecida Fracollia, Maria Fernanda Pereira Gomes ${ }^{b}$, Anna Maria Chiesa ${ }^{c}$}

alislaine@usp.br, bmferpg@usp.br, camchiesa@usp.br

Universidade de São Paulo - São Paulo (SP), Brasil

Data de recebimento do artigo: 28/07/2015

Data de aceite do artigo: 02/10/2015

\section{RESUMO}

Introduçáo: $\mathrm{O}$ agente comunitário de saúde trouxe novas perspectivas para o trabalho na atenção básica como a possibilidade de aproximar as equipes de saúde aos grupos heterogêneos que compóem uma dada população. Nesse sentido, as características peculiares desse profissional podem facilitar a promoção da saúde. Objetivo: pensando no potencial do agente para promover a saúde, esta pesquisa teve como objetivo identificar as percepçóes dos agentes comunitários de saúde sobre o assunto. Método: trata-se de uma pesquisa qualitativa, realizada com onze agentes que trabalham nos municípios de Iepê, Nantes, Quatá e Rancharia, pertencentes à Rede Regional de Atenção à Saúde 11 de Presidente Prudente, SP, Brasil. A técnica escolhida para a coleta de dados foi o grupo focal, e a técnica de análise utilizada foi a "análise de conteúdo". Resultados: as açóes de promoção da saúde nos municípios de pesquisa são pouco desenvolvidas pelos agentes e estão pautadas nas açóes de integração da comunidade aos serviços de saúde e ações para o controle do meio ambiente. Conclusáo: a pouca realização de ações de promoção da saúde está relacionada ao fato de que a maioria dos profissionais não teve nenhum tipo de capacitação para seu trabalho.

Palavras-chave: Promoção da saúde; agentes comunitários de saúde; saúde pública.

\section{ABSTRACT}

Introduction: The community health workers have brought new perspectives to work in primary care as the possibility of bringing closer health teams for the heterogeneous groups that make up a given population. In this sense, the peculiar characteristics of these professionals can facilitate health promotion. Objective: Considering the agent's potential to promote health, this research aimed to identify the perceptions of community health workers on the promotion of the health actions they perform. Method: it is a qualitative study done with eleven community health workers who work in the municipalities of Iepê, Nantes, Quatá and Rancharia, municipalities that belong to the $11^{\text {th }}$ Regional Health Care Net of Presidente Prudente, SP, Brazil. The technique for the data collection was the focal group, and the analysis technique used was "the content analysis". Results: The health promotion actions in the studied municipalities have been barely developed by the community health workers and are based on the community integration to health service and actions for the environment control. Conclusion: Most of these community health workers haven't had any training for their profession, which causes its poor accomplishment.

Keywords: Health promotion; community health workers; public health. 


\section{Introdução}

O Ministério da Saúde propôs em 1994 o Programa de Saúde da Família (PSF), que em 2006 passou a ser denominado Estratégia de Saúde da Família (ESF), com o objetivo de fortalecer o nível primário de atençáo à saúde, introduzindo um modelo de organização das práticas centrado na família, com enfoque territorial e trabalho em equipe, tendo em vista o atendimento das necessidades de saúde da população a partir de sua inserção social, possibilitando entender o processo saúde-doença de forma ampliada e a realizaçáo de intervençôes com alcance para além da dimensão curativa ${ }^{1}$.

Nesse contexto, a Saúde da Família incorporou um novo profissional voltado a contribuir para esse novo processo de cuidar, o agente comunitário de saúde (ACS). A incorporação desse novo ator na equipe de saúde trouxe novas perspectivas para o trabalho na atenção básica à saúde ${ }^{2}$.

Com esse profissional, a equipe de saúde tem a possibilidade de se aproximar dos grupos heterogêneos que compóem uma dada população de determinada área de abrangência, de maneira a contribuir para o conhecimento das peculiaridades e necessidades que emanam dos modos particulares de vida desses grupos, fruto do modo de viver e trabalhar conforme se dá a inserção desses agentes na sociedade ${ }^{2}$.

O trabalho do ACS apresenta três dimensóes ${ }^{3}$ :

- Dimensáo técnica: atende indivíduos e família por meio de açóes de monitoramento de grupos específicos, doenças prevalentes e de risco, a partir de visitas domiciliares e informação em saúde com base no saber epidemiológico e clínico;

- Dimensáo política: o ACS é quem reorienta o modelo de atenção à saúde, de discussão dos problemas e organização da comunidade, auxiliando-a no fortalecimento da cidadania, mediante visitas domiciliarias e educação em saúde com base nos saberes da saúde coletiva;

- Dimensão da assistência social: tentativa de resolver questôes como a de acesso aos serviços.

$\mathrm{Na}$ tentativa de conciliar as três dimensões, o trabalho do ACS apresenta-se de forma conflituosa, o que na prática representa açóes que tendem para um desses polos ${ }^{3}$.

O desenvolvimento desta pesquisa partiu dos questionamentos que surgiram após a realização da pesquisa com os ACS que trabalham nos municípios do Colegiado Gestor Regional (CGR) de Alto Capivari, onde se aplicou um questionário que identificava a frequência de realização das ações que compóem as cinco competências propostas pelo Ministério da Saúde para os ACS: integração da equipe com a população local; planejamento e avaliação; promoção da saúde; prevenção e monitoramento de risco ambiental e sanitário; prevenção e monitoramento de grupos específicos e morbidades ${ }^{4,5}$.

Os resultados da pesquisa que realizamos com os ACS do CGR Alto Capivari identificaram que a competência promoção da saúde é a menos realizada nesses municípios, bem como em São Bernardo do Campo e Maríliaa $^{2,6}$. Essa constatação instigou-nos a pesquisar a percepção dos ACS sobre as açôes de promoção da saúde que realizam.

\section{Metodologia}

A abordagem metodológica escolhida para o desenvolvimento desta pesquisa foi a qualitativa. $\mathrm{O}$ cenário de estudo foi o Colegiado de Gestáo Regional (CGR) Alto Capivari, Estado de São Paulo, Brasil, pertencente à Rede Regional de Atenção à Saúde (RRAS) 11 de Presidente Prudente. Esse CGR é composto pelos municípios de Iepê, João Ramalho, Nantes, Quatá e Rancharia, todos de pequeno porte, e sua população varia de 28.809 habitantes (Rancharia) a 2.750 habitantes (Nantes).

Para descrever e analisar as percepçóes dos ACS em relação à competência promoção da saúde, realizamos um grupo focal, técnica que pode ser utilizada no entendimento das diferentes percepções e atitudes acerca de um fato, prática, produto ou serviço, e sua essência consiste na interaçáo entre os participantes e o pesquisador que objetiva colher dados a partir da discussão focada em tópicos específicos e diretivos ${ }^{7}$.

Para o grupo focal foram convidados 3 ACS de cada município, totalizando 15 . Porém, um município não participou, e outro disponibilizou somente 2 ACS, restando 11 ACS. O grupo consistiu numa reunião de 4 horas no mês de maio de 2011. O deslocamento dos ACS foi feito por transporte contratado pelos pesquisadores.

No grupo foram apresentados sucintamente os resultados da primeira etapa da pesquisa em relação às ações que compóem a competência promoção da saúde e investigou-se como essas ações são realizadas, bem como as percepçóes dos ACS no que tangem essas ações.

A reunião foi gravada após consentimento dos participantes, e posteriormente o material foi transcrito, cuidando-se para preservar a confidencialidade dos sujeitos na divulgaçáo dos resultados.

A técnica de análise escolhida para analisar o material obtido na realização do grupo focal foi a "análise de conteúdo", um conjunto de técnicas que visa a obter por procedimentos sistemáticos a descrição 
do conteúdo das mensagens ${ }^{8}$. A presente pesquisa foi aprovada pelo Comitê de Ética em Pesquisa da Escola de Enfermagem da Universidade de São Paulo e pelos Secretários Municipais de Saúde dos cinco municípios. O número de protocolo do parecer é 963/2010/ CEP-EEUSP.

\section{Resultados e discussão}

Para facilitar a organização e análise dos dados, os ACS participantes do grupo focal receberam uma identificação numérica. A análise de suas respostas permitiu a categorização de três temas: insatisfação dos ACS com o serviço que prestam para a comunidade; dificuldades do trabalho do ACS; e o que é ser um ACS.

Os trechos dos discursos abaixo ilustram a insatisfaçáo dos ACS com o serviço que prestam para a comunidade e o seu descontentamento com a falta de capacitação para o seu trabalho.

ACS 3: "Tem muitas atribuiçóes que não são da gente, e por isso o setor da gente fica a desejar, porque é muita coisa pra se fazer, você tem que entregar convite, tem que entregar encaminhamentos".

ACS 1: "Nós estamos fazendo várias funçôes, e se o nosso trabalho realmente é de ACS, acaba ficando de lado, então dai essa prevenção, esse diálogo com o morador não está havendo com o paciente, não está sendo uma visita de qualidade".

A fala dos ACS reflete sua insatisfação em realizar certas tarefas que são designadas a eles. Por falta de uma clara delimitação de suas atribuiçóes, o ACS tem sido designado a realizar qualquer ação para as famílias e comunidade?

Num estudo realizado em Porto Alegre, destacou-se que o ACS realiza atividades de apoio à equipe de saúde, como recepcionar o usuário na unidade de saúde, buscar prontuários, atender aos telefonemas, organização e controle do almoxarifado ${ }^{10}$. Os ACS podem desenvolver açóes de apoio à equipe de saúde, mas o desenvolvimento dessas açóes não pode virar uma rotina, de forma que o ACS, ao trabalhar nas unidades de saúde, esqueça-se do seu papel com as famílias.

O ACS deve realizar as ações relacionadas com a comunidade, fortalecendo seu conhecimento das diversas implicaçôes no cotidiano das famílias, mas não se pode também delegar ao ACS qualquer atribuição, de forma que seu papel seja distorcido e fuja do objetivo principal de capacitar a comunidade para melhorar sua qualidade de vida.
ACS 6: "No meu caso eu não fiz curso nenhum de ACS [...] Eu entrei e fui aprendendo [...] Se você tiver embasamento [...] um curso que você tenha duas vezes por ano para te dar base daquilo ali que você está fazendo, é muito mais fácil para você".

Observa-se nas falas dos ACS que no CGR Alto Capivari eles não são capacitados para atuar junto às famílias, o que pode causar problemas para essa função. A capacitação tem papel relevante para o desenvolvimento do trabalho do ACS, pois é capaz de fornecer a esse trabalhador conhecimentos acerca do processo saúde-doença em todas as suas dimensóes e de outros saberes que o habilitam na interação com as famílias e no reconhecimento de suas necessidades ${ }^{10-12}$. É imprescindível que os ACS sejam capacitados para desenvolver o rol de suas atribuiçóes de forma a produzir resultados positivos na vida das famílias.

Para que os ACS não sejam meros transmissores de informações, eles devem ser capazes de ensinar as famílias e comunidades, atuando de forma crítica e problematizando a realidade vivida por essas pessoas ${ }^{13}$. O processo de qualificação do ACS deve ter como ponto de partida o processo educativo crítico, que é mais do que incorporar conteúdos específicos - é fazer, de modo cada vez mais aprofundado e consistente, a "leitura do mundo" que nos cerca. É por isso que, na perspectiva da educação popular, aprender é também construir saberes $^{14}$.

Para isso, os conteúdos a serem abordados devem ser explorados com base em perspectivas autênticas da prática, considerando sua consistência e funcionalidade para o enfrentamento de situaçóes reais, de forma que a reconstrução de significados ultrapasse uma aprendizagem baseada simplesmente na reprodução teórica do conhecimento e se converta em uma aprendizagem que tenha como pressuposto a participaçáo ativa do ACS e uma efetiva integração da teoria com a prática ${ }^{15}$.

A Organização Mundial da Saúde (OMS) e a Estratégia de Saúde da Família (ESF), devido ao amplo papel que os ACS desempenham nos cuidados primários à saúde, devem garantir que um conjunto básico de habilidades e informações relacionadas aos desafios do milênio seja fornecida para a maioria dos ACS. Portanto, o currículo deve incorporar o conhecimento científico sobre prevenção e cuidados médicos básicos e relacionar essas ideias às questóes locais e tradiçóes culturais. Eles devem ser capacitados para desenvolver açóes de promoção, prevenção e de reabilitação relacionadas à saúde materna, neonatal, infantil, malária, tuberculose, HIV/ AIDS, bem como outras doenças transmissíveis e não transmissíveis. Outros conteúdos de formação pertinentes para o trabalho podem ser adicionados à intervenção específica do $\mathrm{ACS}^{16}$. 
O ACS deve, portanto, considerar seu papel como o de um educador, por sua inserção como sujeito popular e ao mesmo tempo vinculado aos serviços. Ele deve se pautar por pressupostos pedagógicos críticos ${ }^{17}$. Nessa perspectiva, salienta-se a importância de que todos os ACS, demais profissionais que trabalham na saúde da família e gestores sejam capacitados a desenvolver o pensamento crítico a partir das realidades em que se inserem, para que o processo de educação popular possa avançar para processos de transformação da realidade, refletindo-se em melhorias das condiçôes de vida e saúde da população.

$\mathrm{O}$ trecho dos discursos abaixo revelam as dificuldades que os ACS encontram no desenvolvimento de seu trabalho, pois atuam junto às famílias sob a perspectiva de quantidade, ocorrendo uma baixa adesão das equipes de saúde à reunião de equipe.

ACS 9: "Na verdade você não faz uma coisa pela qualidade, mas pela quantidade. Na hora de você passar o SIAB interessa o número, o minimo, e não a qualidade".

A fala dos ACS permite identificar que as açóes realizadas pelos ACS que trabalham no CGR Alto Capivari sáo operacionalizadas na perspectiva de atender uma meta quantitativa. Ou seja, os ACS realizam uma visita mensal a todas as famílias pelas quais é corresponsável sem fazer o mapeamento de risco. A saúde da família tem como objetivo intervir sobre os fatores de risco aos quais a população está exposta; proporcionar o estabelecimento de parcerias por meio do desenvolvimento de ações intersetoriais; contribuir para a democratização do conhecimento do processo saúde-doença, da organização dos serviços sociais de saúde; reconhecer a saúde como um direito de cidadania e, portanto, expressão da qualidade de vida; estimular a organizaçáo da comunidade para o efetivo exercício do controle social ${ }^{18}$.

Quando os ACS em conjunto com a equipe de saúde não fazem o mapeamento de risco, trabalham para a comunidade desprovidos do princípio de equidade, não favorecendo as famílias que mais necessitam de saúde.

ACS 7: "Nós só temos reuniāo de equipe quando acontece algo muito grave";

ACS 3: "Nós não temos tempo de fazer reuniāo de equipe"; ACS 6: "A gente não tem reunião de equipe, a gente tem um caderninho de ocorrências [...] que a nossa enfermeira propôs para gente [...] se der alguma ocorrência a gente escreve no caderno".

A fala dos ACS demonstra que a reunião de equipe é pouco praticada no CGR Alto Capivari, o que demonstra problemas de comunicação e relacionamento interpessoal entre esses profissionais, resultando em açóes de saúde fragmentadas e desarticuladas do contexto social e das necessidades das famílias. Com isso, deixa-se de consolidar um dos pilares diferenciadores da ESF.

Ressalta-se que as reunióes de equipe no cotidiano de trabalho são importantes dispositivos para a estruturação, organização, informação, troca de saberes, estabelecimento de diretrizes e espaço de tomada de decisóes. É no momento da reunião de equipe que os trabalhadores podem expressar suas opiniōes, construir projetos e planos de atendimento coletivos para a construção de um projeto terapêutico assertivo e embasado nas necessidades de saúde da comunidade. Desse modo, as reuniōes de equipe são importantes dispositivos para redirecionar o trabalho, por meio de discussão de casos em uma perspectiva interdisciplinar, desenvolvimento de atividades em educação permanente e avaliação sistemática do cotidiano da equipe ${ }^{19}$.

Os trechos mencionados abaixo apontam que a falta de definição do papel do ACS revela um confronto de identidade que remete o ACS a confundir suas funçóes, resultando numa baixa autoestima e angústia no desempenho de seu trabalho.

ACS 6: "Ninguém sabe qual é a nossa função na realidade. Promover a saúde, mas como fazer isso que está complicado".

ACS 3: "Tinha que ter o que realmente é a função do ACS".

Observa-se que os entrevistados não sabem qual é o seu papel junto à comunidade. $\mathrm{O}$ trabalho do ACS deve ser uma extensão dos serviços de saúde dentro das comunidades, já que ele mesmo é um membro da comunidade e possui com ela um envolvimento pessoal ${ }^{20}$.

Segundo o Ministério da Saúde, ser ACS é, antes de tudo, ser alguém que se identifica em todos os sentidos com a sua própria comunidade, principalmente na cultura, linguagem e costumes. O ACS deve ser o membro da equipe de saúde mais próximo dos problemas que afetam a qualidade de vida das famílias e se destacar pela capacidade de se comunicar com as pessoas e pela liderança natural que exerce ${ }^{20}$.

As açóes desenvolvidas pelos ACS nas comunidades devem favorecer a transformação de situaçóes-problema que afetam a qualidade de vida das famílias, como aquelas associadas ao saneamento básico, destinação do lixo, condiçóes precárias de moradia, exclusão social, desemprego, violência intrafamiliar e drogas lícitas e/ou ilícitas ${ }^{20}$.

Uma pesquisa realizada no município de São Paulo sobre a identidade do ACS revelou quatro dimensóes relacionadas à formaçáo da identidade ocupacional social do ACS: 1) profissáo, saber e regulamentação; 2) 
identidade e organização do trabalho, transitando entre os polos burocrático e profissional, regras e respaldo social; 3) identidade no pertencer a um determinado grupo, tentando identificar o que determina a coesão interna e a sua diferenciação; 4) características dos modos de assistência na saúde e das funçóes dos profissionais ${ }^{21}$.

De acordo com a OMS, os ACS são trabalhadores de base comunitária que ajudam os indivíduos e grupos das comunidades a acessar serviços de saúde e serviços sociais, educando os membros da comunidade sobre os diversos problemas de saúde ${ }^{16}$.

Uma pesquisa realizada no município de Marília (SP) identificou que o fato do ACS conhecer a comunidade e fazer parte dela proporciona ganhos no trabalho com as famílias. Saber/viver o que acontece no dia a dia possibilita um olhar e uma escuta ampliada dos problemas, favorecendo o colocar-se no lugar do outro (comunidade), ou melhor, ser a extensão do outro ${ }^{22}$.

Quando analisamos o trabalho do ACS que atua no CGR Alto Capivari, observa-se que as açôes de saúde desenvolvidas por eles junto às famílias os caracterizam no polo mais técnico, pois interagem com as famílias transmitindo informaçōes prescritivas para melhoras na saúde, sem com isso desenvolver o pensamento crítico das famílias sobre suas condiçóes de vida e saúde. Nessa conjuntura, o envolvimento com seu polo comunitário fica esquecido, o ACS tem o anseio de ser um membro da equipe de saúde com saberes técnicos e científicos e pouco valoriza sua identidade de membro da comunidade que pode agir de forma transformadora junto às famílias, no que tange ao fortalecimento das comunidades para buscarem condiçôes mais dignas de vida e saúde.

Embora o ACS possua grande potencial para promover a saúde, seu processo de trabalho é fragmentado por causa do desconhecimento desses profissionais de sua identidade, ou seja, de qual é o seu papel junto às famílias.

Sabendo que o desenvolvimento da capacitação dos ACS do CGR Alto Capivari é primordial para os avanços e resultados positivos na saúde da região, busca-se resgatar os preceitos da Política Nacional de Educação Permanente (PNEPS), o que representaria uma importante mudança na concepção e nas práticas de capacitação dos trabalhadores dos serviços de saúde ${ }^{23}$.

As Comissóes de Integração Ensino e Serviço (CIES) são instâncias colegiadas intersetoriais e interinstitucionais permanentes que participam da formulação, condução e desenvolvimento da PNEPS. Atualmente, configuram-se cinco CIES no estado de São Paulo, compondo macrorregióes que integram os dezessete Departamentos Regionais de Saúde (DRS) e os sessenta e quatro Colegiados de Gestáo Regional (CGR) ${ }^{23}$.

A condução regional da EP se dá por meio dos CGR. Tendo em vista os preceitos de operacionalização da PNEPS, a CIES Macro Oeste Paulista que integra a
DRS XI Presidente Prudente e o CGR Alto Capivari, os gestores municipais de saúde e os profissionais de saúde que atuam nas equipes de saúde devem avaliar a capacitaçáo periodicamente e oferecer o aprimoramento profissional, instrumentalizando os profissionais de nível superior que atuam nas unidades de saúde a capacitar os ACS conforme as necessidades da população e as situaçóes de vulnerabilidade encontradas. A supervisão do trabalho do ACS deve ser contínua para que as arestas encontradas no desenvolvimento de seu trabalho sejam corrigidas e as necessidades de capacitação resolvidas.

Diante dos resultados encontrados na pesquisa desenvolvida no CGR Alto Capivari, é importante destacar os pressupostos que a Organização Mundial da Saúde traz sobre como os programas de ACS devem ser. Em uma breve revisão, a OMS diz que os programas de ACS devem apoiá-los, avaliar continuamente as necessidades da comunidade no fornecimento de suprimentos essenciais e equipamentos necessários e adequados para melhorar seu trabalho ${ }^{16}$.

Os programas de ACS também devem proporcionar oportunidades para a mobilidade de carreira e desenvolvimento profissional, incluindo oportunidades de educaçáo continuada, profissional, reconhecimento e progressáo na carreira. Isso pode ocorrer por meio de oportunidades programáticas específicas ou de acesso a bolsas de estudo e formação ${ }^{16}$.

\section{Conclusão}

Os ACS que atuam no CGR Alto Capivari não reconhecem em suas ações o potencial de mudar a saúde das famílias pois a maioria deles não passou por nenhum tipo de capacitação para seu trabalho. Outro aspecto importante é que os ACS apresentam-se com autoestima baixa em relação ao trabalho, o que compromete sua motivação e pode diminuir a efetividade e produtividade no desenvolvimento das açóes previstas. Observou-se também que o trabalho do ACS está voltado para as necessidades da equipe em cumprir metas e não para as necessidades da população.

Os ACS em conjunto com as equipes não trabalham com mapeamento de risco, o que resulta numa ação com pouca equidade para as famílias. No que tange à educaçáo popular, observa-se que o ACS passa as orientaçóes de saúde para a comunidade de forma prescritiva, não desenvolvendo o pensamento crítico das pessoas para cuidarem de sua saúde.

Identificou-se com o desenvolvimento desta pesquisa que a falta de capacitação é o grande entrave que produz os demais problemas encontrados, e que os ACS do CGR Alto Capivari precisam ser capacitados para que suas ações possam trazer resultados positivos 
e a emancipaçáo dos sujeitos. Outro ponto importante é que o ACS não é o único responsável pelos avanços nas açóes de promoção da saúde: dependem também do esforço coletivo dos pacientes, profissionais e gestores de saúde.

$\mathrm{Na}$ verdade, o que se desenha da prática do ACS no CGR Alto Capivari é que ele integra a comunidade aos serviços de saúde e realiza açóes para o controle do meio ambiente. As consideraçóes da OMS sobre como deve ser um programa de ACS podem ser seguidas pelo Ministério da Saúde para construir um programa de ACS com maior efetividade e produtividade.

\section{Referências}

1. Franco T, Merhy E. PSF: Contradiçôes e novos desafios. In: 10a Conferência Nacional de Saúde Online; 1996. Brasília (DF), BR. Brasília: Ministério da Saúde; 1996. Disponível em: http://www.datasus.gov.br/cns/cns.htm.

2. Santos LPGS. A atuação do agente comunitário de saúde em São Bernardo do Campo: possibilidades e limites para a promoção da saúde [dissertação]. São Paulo: Escola de Enfermagem, Universidade de São Paulo; 2005.

3. Chiesa AM, Fracolli LA. O trabalho dos agentes comunitários de saúde nas grandes cidades: análise do seu potencial na perspectiva da promoção da saúde. Rev Bras Saúde Fam. 2004;5(7):42-9.

4. Gomes MFP. As potencialidades do agente comunitário de saúde para açốes de Promoção da Saúde: em foco o Colegiado Gestor Regional de Alto Capivari [dissertação]. São Paulo: Escola de Enfermagem, Universidade de São Paulo; 2011.

5. Ministério da Saúde (BR). Ministério da Educação. Referencial curricular para o curso técnico de agente comunitário de saúde: área profissional. Brasília (DF): Ministério da Saúde; 2004.

6. Pinto AAM. As potencialidades do agente comunitário de saúde na efetivação da promoção da saúde: uma análise das suas ações no município de Marília-SP [dissertação]. São Paulo: Escola de Enfermagem, Universidade de São Paulo; 2010 .

7. Lervolino SA, Pelicioni MCF. A utilização do grupo focal como metodologia qualitativa na promoção da saúde. Rev Esc Enferm USP. 2001;43(2):115-21.

8. Bardin L. Análise de conteúdo. Lisboa: Ediçôes 70; 1970.

9. Ferraz L, Aertes DRGC. O cotidiano de trabalho do agente comunitário de saúde no PSF em Porto Alegre. Ciênc saúde coletiva. 2005;10:347-55.

10. Freitas AC, Silva LCP, Jesus MB, Kumanaya MF, Silva GTR. Desvelando a vivência de uma equipe multiprofissional de residentes em Saúde da Família com o agente comunitário de saúde. Rev APS. 2007;10(2):143-55.

11. Nunes MO, Trad LB, Almeida BA, Homem CR, Melo MCIC. O agente comunitário de saúde: construçáo da identidade desse personagem híbrido e polifônico. Cad Saúde Pública. 2002;18(6):1639-46.

12. Duarte RL, Silva Junior DS, Cardoso SH. Construindo um programa de educação com agentes comunitários de saúde. Interface. 2007;11(23):439-47.

13. Fontoura MD, Almeida AP, Marques CMS, Prado MM, Cordón J. Dilemas bioéticos no cotidiano do trabalho do agente comunitário de saúde. Rev. saúde Dist Fed. 2004; 15:67-77.

14. Freire P. Pedagogia do oprimido. Rio de Janeiro: Paz e Terra, 1970. 220 p.

15. Mendes EV. SUS: um processo social em construção. Disponível em: <http://www.opas.org.br/rh/publicacoes/ textos_apoio/ACF9371.pdf> Acesso em: 28 jun. 2010.

16. World Health Organization (WHO). Global experience of community health workers for delivery of health related millennium development goals: a systematic review. Country Case Studies, and Recommendations for Integration into National Health Systems. Pakistan; 2010.

17. Stotz EN, David HMSL, Bornstein VJ. O agente comunitário de saúde como mediador: uma reflexão na perspectiva da educação popular em saúde. Rev APS. 2009;12(4):487-97.

18. Papoula SR. O processo de trabalho intersetorial das equipes de saúde da família no município de Petrópolis-RJ: fatores restritivos e facilitadores [dissertação]. Rio de Janeiro: Escola Nacional de Saúde Pública Sergio Arouca; 2006.

19. Grando MK, Dall'agnol CM. Desafios do processo grupal em reuniōes de equipe da estratégia saúde da família. Esc Anna Nery Rev Enferm. 2010;14(3):504-10.

20. Silva KL, Sena RR. Poder, Autonomia e Responsabilização: promoção da saúde em espaços sociais da vida cotidiana. Editora Hucitec: Rio de Janeiro; 2010.

21. Silva JA, Dalmaso ASW. Agente comunitário de saúde: o ser, o saber, o fazer. Rio de Janeiro: Editora Fiocruz; 2002.

22. Peres CRFB. O trabalho do agente comunitário de saúde no município de Marília-SP [dissertação]. Botucatu: Faculdade de Medicina, Universidade Estadual Paulista; 2006.

23. Ministério da Saúde (BR). Política nacional de educação permanente em saúde. Brasília (DF): Ministério da Saúde; 2009.

\section{Como citar este artigo:}

Fracolli LA, Gomes MFP, Chiesa AM. Percepçôes dos agentes comunitários de saúde sobre as açôes de promoção da saúde. Rev. Aten. Saúde. 2016;14(47): 49-54. 